DOI: $10.17805 /$ zpu.2015.4.28

\title{
Кинорепертуар и зрительские предпочтения в эпоху «оттепели» в России
}

\author{
М. И. КОСИНОВА
}

(ГОСУДАРСТВЕННЫЙ УНИВЕРСИТЕТ УПРАВЛЕНИЯ; ВСЕРОССИЙСКИЙ ГОСУДАРСТВЕННЫЙ УНИВЕРСИТЕТ КИНЕМАТОГРАФИИ ИМ. С. А. ГЕРАСИМОВА, Г. МОСКВА)

Рассматриваемый в статье период «оттепели» считается эпохой расцвета советского кино, когда к нему было приковано внимание не только отечественной, но и мировой киноаудитории. В этот период в нашей стране наблюдалась самая высокая кинопосещаемость за всю историю существования отечественного кинематографа (около 4 млрд посещений в год). Учитывая нынешнее плачевное положение отечественного кинематографа, его непопулярность у зрительской аудитории, опыт «оттепельного» кинематографа является очень полезным, поучительным и актуальным.

Целью работы является выявление причин успеха «оттепельного» кино у зрительской аудитории. Это поможет нам определить вектор современной репертуарной политики российского кино, сориентировать его на аудиторию и разрешить проблему диссоциации отечественного кинематографа и зрителя. В связи с данной целью задачами работы являются изучение репертуарной политики «оттепельного» кино в России, результатов социологических исследований зрительской аудитории того времени и среза критической мысли.

Репертуарная политика «оттепельного» кино была ориентирована на зрителя. Большое внимание уделялось развлекательной составляющей. Но это делалось (за редким исключением) не в угоду общему качеству картины. Если проводить параллели с настоящим временем, то нетрудно заметить, что сегодня развлекательная функция кино превалирует, а все остальные (воспитательная, просветительская и пр.) остаются далеко позади или чаще вообще игнорируются создателями фильмов (как российских, так и зарубежных).

Успех развлекательного, жанрового кинематографа у широкой зрительской аудитории способствовал формированию особого жанра советской кинокритики - фельетона о коммерческом фильме, затем стали выходить статьи, в которых учитывалась специфика жанрового кино. Социологические исследования тех лет показывают, что независимо от обстоятельств у так 
называемого трудного фильма в советское время была очень стабильная аудитория. Эта категория зрителей (профессионалы, любители, подготовленная аудитория) была лидером мнения, непосредственно влияла на общественное признание того или иного авторского фильма. Появились киноклубы любителей кино при вузах, НИИ, различных предприятиях. Просмотры картин в них сопровождались их обсуждением, что значительно повышало коэффициент полезного воздействия кино на зрителя.

Ключевые слова: история кинематографа; российский кинематограф; «оттепель»; репертуарная политика; кинозритель; киноаудитория; кинопосещаемость; кинопрокат

\section{ВВЕАЕНИЕ}

$\mathrm{E}$ сть мнение, что в настоящее время наше кино находится на подъеме, кассовые сборалы растут с каждым годом, и никаких существенных проблем в этой области нет. Однако, по нашему мнению, современное российское кино пребывает в глубоком затяжном кризисе. Кризис этот является системным и имеет множество аспектов, рассмотреть которые здесь не представляется возможным в силу небольшого объема статьи. Мы же сконцентрируем свое внимание на вопросе репертуарной политики. Этот вопрос является одним из ключевых, поскольку неверный вектор развития репертуарной политики, по сути, перечеркивает все остальные благие намерения в области развития киноотрасли. Сегодня много говорят о недостаточном государственном финансировании киноотрасли. Но при простом увеличении, пусть даже значительном, суммы вложений результат вряд ли изменится. Аело не в цене вопроса, а в том, что именно поддерживать, какие именно фильмы. Как раз на этой линии фронта сегодня у нас наблюдаются самые большие потери. Из года в год на киноэкраны выходит огромное количество слабых, скучных, ничем не примечательных российских фильмов, из-за которых кредит доверия к современному российскому кино перманентно падает. Как переломить эту печальную тенденцию? На наш взгляд, ответ надо искать в истории. И не случайно мы обращаемся к одному из самых успешных и ярких периодов в истории отечественного кино - периоду «оттепели».

Этот период представляет для нас интерес по той причине, что в те годы кино являлось поистине важнейшим из искусств. Телевидение на тот момент еще не получило массового распространения, а другие способы проведения досуга (театр, концерты и пр.) уступали кинематографу по посещаемости. На первый взгляд может показаться, что экстраполяция «оттепельного» опыта на современные реалии является неправомерной - в век расцвета компьютерных технологий кинематограф не может занимать столь же высокие позиции в орбите зрительского внимания. Однако найденный «оттепельным» кино ключ к сердцу зрителя, на наш взгляд, можно и нужно использовать и сегодня. Аюди меняются не так быстро, как технологии. И та система ценностей, которая была отражена в кино 1950-1960-х годов, не устарела. По крайней мере, хочется на это надеяться. Этим объясняется актуальность и значимость данной работы.

Целью исследования, таким образом, является выявление причин успеха «оттепельного» кино у зрительской аудитории. В связи с данной целью задачами работы являются изучение репертуарной политики «оттепельного» кино, социологических исследований зрительской аудитории, среза критической мысли. Анализ зрительских предпочтений поможет нам выявить закономерности, которые можно использовать при разработке современной репертуарной стратегии.

Научной разработкой данной тематики занимались такие авторы, как М. И. Жабский, Ю. У. Фохт-Бабушкин, К. А. Тарасов (Жабский, Тарасов, Фохт-Бабушкин, 2000; 
Жабский, 2009; Фохт-Бабушкин, 2001; Феномен массовости кино, 2004; Полюса кинопроцесса ... , 2007), Н. М. Зоркая (Зоркая, 1981, 1994, 1998), А. А. Рондели (Рондели, 2013), В. И. Фомин (Фомин, 1996, 2012; Кинематограф оттепели ..., 1998), Н. А. Хренов (Хренов, 2002) и ар.

В книгах М. И. Жабского собраны исследовательские работы социологов НИИ киноискусства, имеющие своей целью поиск путей выхода отечественного кино из затяжного кризиса. В его работах, как и в трудах $\Lambda$. А. Рондели, содержится весьма ценная информация для деятелей отечественного кинематографа, пытающегося обрести свою конкурентоспособную идентичность в условиях, когда большинство реальных кинозрителей безоговорочно предпочитают «голливудское меню». Книга Н. М. Зоркой «Уникальное и тиражированное» (Зоркая, 1981) посвящена кругу проблем, связанных с бытием, судьбой искусства в эпоху научно-технической революции и вызванными ею процессами демократизации художественной культуры, включением в ее орбиту новых массовых видов и форм художественного творчества. В другой работе автора - «Фольклор. Аубок. Экран» (Зоркая, 1994) - представлен новый, оригинальный взгляд на эстетическую систему современных массовых форм искусства, присущий автору книги, позволяет вскрыть истоки популярных экранных зрелищ. Яркие, насыщенные конкретным материалом страницы посвящены литературному лубку, балаганному театру, ярмарочным представлениям Петрушки - предтечам многосерийного телевизионного фильма - фаворита кинематографических массовых жанров (детектива, мелодрамы и т. А.).

Ту же тему поднимает В. И. Фомин в своей книге «Правда сказки. Кино и традиции фольклора» (Фомин, 2012). В книге впервые на теоретическом уровне обобщен огромный и поистине уникальный опыт отечественного кино в освоении традиций народной культуры, выявлены и проанализированы основные формы и принципы взаимодействия кино с миром фольклора. Аругие книги автора (Кинематограф оттепели ..., 1998; Фомин, 1996) посвящены анализу организационно-экономической модели киноотрасли, управленческого, цензурного аппарата.

В монографии Ю.У. Фохт-Бабушкина (Фохт-Бабушкин, 2001) рассматривается история конкретно-социологических исследований функционирования различных видов искусства и опытов комплексного анализа художественной жизни России второй половины XX в. Обобщая результаты многих сотен исследований, автор дает характеристику эволюции взаимоотношений публики и искусства, выявляет узловые теоретико-методологические проблемы, волновавшие исследователей: принципы целостного изучения функционирования искусства в обществе, типологический подход к рассмотрению аудитории искусства, его роль в развитии дичности, характер качественных и количественных показателей конкретно-социологических исследований, использование такого рода исследований в принятии управленческих решений по организации художественной жизни общества и т. А.

Во всех перечисленных работах репертуарная политика является одним из рассматриваемых аспектов. Мы же сфокусируемся на вопросе репертуарной политики, ориентированной на зрителя, как на основополагающем.

\section{РЕПЕРТУАР «ОТТЕПЕАЬНОГО КИНО}

Эпоха «оттепели» - один из самых ярких периодов в истории советского кино. Особенно выигрышно и впечатляюще результаты «оттепельного» кинематографа смотрятся на фоне предыдущего периода «малокартинья» (1943-1953). Цепная реак- 
ция перемен, происходящих в разных сферах советской культуры и искусства после смерти И. В. Сталина, не обошла стороной и кинематограф. Эти перемены способствовали быстрому качественному и количественному росту нашего кинематографа, что, в свою очередь, положительно отразилось на кинопосещаемости.

К концу 1950-х годов кинопосещаемость в СССР превысила 3 млрд человек против 1,5 млрд в 1953 г. Валовой сбор средств от киносеансов по государственной киносети возрос до 5,5 млн руб. в 1957 г., а по всей киносети - до 7,5 млн руб. На 1 января 1958 г. киносеть насчитывала около 80 тыс. киноустановок, в том числе свыше 50 тыс. на селе (История киноотрасли в России ..., 2012; Аетопись российского кино ... , 2010: 400).

К этому времени были освоены новые для нашей страны виды кинематографа широкоэкранный, панорамный, широкоформатный, круговая панорама. Полностью было освоено цветное кино.

В конце 1950 - начале 1960-х годов жанрово-тематический диапазон советского кинематографа значительно расширился. С одной стороны, кинематографисты обратили взгляд в прошлое, к традиции 1930-х годов, когда удачное сочетание лирического, эпического и эксцентрического начал давало блестящий результат. От предшествующего периода «оттепельное» кино унаследовало традицию четкого разделения на жанрово-тематические пласты: военный, историко-революционный, колхозный, производственный и т. д.

С другой стороны, «оттепельный» кинематограф характеризуется более пристальным вниманием к внутреннему миру человека (независимо от жанра и темы фильма). Причем не былинного героя, не великого политического деятеля, полководца или музыканта, а самого что ни на есть обыкновенного, рядового человека.

Максимальное приближение кинематографа к жизненным реалиям способствовало утверждению на экране фильмов на острые современные темы. Сюда можно отнести и «производственные» («Коммунист» Ю. Райзмана, 1957), и «деревенские» фильмы (картины В. Шукшина; «Председатель» А. Салтыкова, 1964), и фильмы, посвященные научным достижениям («Аевять дней одного года» М. Ромма, 1961). Во времена «оттепели» как никогда востребованным оказался интеллектуальный фильм ( «амлет» Г. Козинцева, 1964; фильмы А. Тарковского). Больше внимания стало уделяться детям ( «Сережа» Г. Аанелии и И. Таланкина, 1960; «Человек идет за солнцем» М. Калика, 1961; «Звонят, откройте дверь» А. Митты, 1965) и молодежи. Особое значение приобрела тема вступления молодого человека в жизнь («Мне двадцать лет» (1965) и «Июльский дождь» (1967) М. Хуциева). По-новому, под иным ракурсом была раскрыта тема войны. Фильмы именно этой тематики принесли мировую славу советскому кино на заре «оттепели» («Аетят журавли» М. Калатозова, 1957; «Судьба человека» С. Бондарчука, 1959; «Баллада о солдате»Г. Чухрая, 1959; «Мир входящему» А. Алова и В. Наумова, 1961).

В период «оттепели» популярными были детективный и комедийный жанры. На волне первого возникли многочисленные сериалы, чрезвычайно востребованные зрителем ( «Семнадцать мгновений весны» Т. Аиозновой, 1973; трилогия о «Неуловимых мстителях» Э. Кеосаяна, 1966; и т. А.). Второй же - комедийный - жанр характеризовался в это время небывало широким разнообразием: легкая, лирическая комедия ( «Аевчата» Ю. Чулюкина, 1961); феерическая, эксцентрическая (фильмы Р. Быкова, А. Гайдая); социальная («Я шагаю по Москве» Г. Аанелии, 1963); гротесковая ( «Скверный анекдот» А. Алова и В. Наумова, 1966; «Аобро пожаловать, или Посторонним вход воспрещен» Э. Климова, 1964; «Тридцать три» Г. Аанелии, 1965) и т. А. 
В результате реабилитации в рассматриваемый период многих запрещенных прежде писателей расширилась орбита экранизируемой литературы. Изменился и ракурс экранизаций, которые быстро избавились от навязываемых прежде элементов «большого» стиля. В эпоху «оттепели» киноэкранизации обрели вторую жизнь спустя очень продолжительный период, они наполнились живыми, узнаваемыми образами, приметами времени, обрели определенную авторскую стилистику и перестали напоминать один большой фильм, как это было в последние годы сталинского периода.

Во время «оттепели» было поставлено множество выдающихся произведений русской и мировой литературы ( «Отелло»С. Юткевича, 1955; «Гамлет» (1964) и «Король Иир» (1970) Г. Козинцева; «Идиот» (1958) и «Братья Карамазовы» (1968) И. Пырьева; «Война и мир» С. Бондарчука, 1966-1967; «Аама с собачкой» И. Хейфица, 1959; и др.).

\section{ЗРИТЕАИ И КРИТИКИ}

Расширение репертуарного диапазона, возможность выбора в корне изменили всю систему отношений между кино и зрителем. «В критических статьях и обзорах журнала "Искусство кино", - отмечает М. Р. Зезина, - ссылки на мнения зрителей стали встречаться даже чаще, чем на партийные решения и выступления руководителей. Социологические исследования зрительской аудитории тогда еще не проводились, но редакция получала множество писем и по ним могла судить о настроениях зрителей. Фактически у кинематографа появился новый заказчик - зритель, запросы которого далеко не всегда совпадали с требованиями, которые выдвигала власть. $<\ldots .>3$ ритель становился уже не столько объектом идейно-воспитательного воздействия, сколько заказчиком, имеющим право заявлять о своих требованиях и предъявлять претензии. Хотя отношения со зрителем складывались неоднозначно, особенно когда зрительские оценки расходились с мнением критики» (Зезина, 2004: 396-397).

Несовпадение оценок зрителей и критики того или иного фильма появилось еще в дореволюционную эпоху. Разрыв между суждением о фильме кинокритики и массовой киноаудитории продолжал существовать и в советское время, особенно в 1920-е годы, когда зритель еще имел возможность выбирать между «идеологической» и «кассовой» лентой. Позднее, в 1930-х годах, ножницы между критической мыслью и мнением широкой зрительской аудитории если и не смыкаются, то зазор между ними становится едва уловимым. И лишь в эпоху «оттепели» орбиты профессиональной киносреды и простого зрителя разошлись, а зачастую стали приобретать противоположные направления. В это время на массовую и элитарную разделилась и кинопресса. Так, журнал «Искусство кино» стал журналом, адресованным профессионалам, a «Советский экран» стал массовым изданием для самой широкой публики.

В конце 1950-х годов наибольшим успехом у зрителей пользовались фильмы с занимательной фабулой, комедии, научно-фантастические и приключенческие картины, детективы, в то время как критики и киноведы относились к этим жанрам настороженно (Кино и зритель ..., 1968: 111, 113). Наиболее успешными в прокате фильмами этого периода были «Укротительница тигров» (А. Ивановский, Н. Кошеверова, 1954), «Педагогическая поэма» (А. Маслюков, М. Маевская, 1955), «Ава капитана» (В. Венгеров, 1955), «Аело Румянцева» (И. Хейфиц, 1956). Они заработали в прокате 91,7, 80,7, 75,7 и 75 млн руб. соответственно. Кассовый успех фильма определяли главным образом вкусы молодежи, которая преобладала среди кинозрителей (в основном школьники старших классов, студенты техникумов и вузов). Также популярны были картины «Над Тиссой» (А. Васильев, 1958), «Карнавальная ночь» (Э. Ряза- 
нов, 1956), «Свадьба с приданым» (Т. Аукашевич, Б. Равенских, 1953), «Застава в гоpax» (К. Юдин, 1953), «Иван Бровкин на целине» (И. Аукинский, 1958), «Голубая стре-

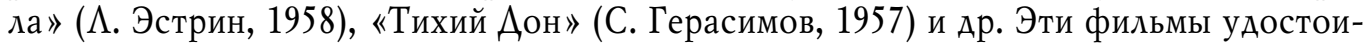
лись внимания более чем 40 млн зрителей каждый.

Из зарубежных лент в конце 1950 -х годов особой любовью у киноаудитории пользовались американские приключенческие ленты о Тарзане режиссера Р. Торпа ( Тарзан в западне», 1936; «Приключения Тарзана в Нью-Йорке», 1942). Снятые в Голливуде в 1930-1940-х годах, они попали на советский экран лишь в начале 1950-х и сразу завоевали огромную зрительскую любовь.

Однако рекордсменом, надолго покорившим сердца советских зрителей, стал индийский фильм «Бродяга» режиссера Р. Капура 1951 г. (63,7 млн зрителей).

Ао конца 1940-х годов какие-либо азиатские фильмы отсутствовали в советском прокате. Но в послевоенные годы отношения СССР с некоторыми колониальными странами начали меняться, поскольку начала меняться политическая ситуация в этих странах. Вторая мировая война ускорила развитие национально-освободительного движения в Азии, Африке и Аатинской Америке, способствовала процессу распада колониальной системы империализма. В результате победы над фашистской Германией и милитаристской Японией в исторически короткие сроки сбылись чаяния многих народов колониальных и зависимых стран о завоевании национального суверенитета. Одной из первых избавилась от колониальной зависимости Индия. В результате чего высшее руководство СССР «оживилось», так как возникло искушение вовлечь Индию в сферу советского вдияния. Между Индией и Советским Союзом быстро наладился прямой товарообмен, а обмен культурными ценностями стал самым интенсивным. Так что продукция «Болливуда» составила в советском прокате огромную конкуренцию американской.

Иидерами проката на заре «оттепели» были комедии и приключенческие (шпионско-героические) фильмы. В то же время зритель абсолютно не принимал историкобиографический жанр, опостылевший ему в сталинскую эпоху. Такие картины, как «Борис Годунов» (В. Строева, 1954), «Михайло Аомоносов» (А. Иванов, 1955), «Иван Грозный» (2-я серия, С. Эйзенштейн, 1958) проваливались в прокате (их посмотрели $13,19,5$ и 10 млн зрителей соответственно). Значительно хуже то, что ни в первую, ни во вторую десятку наиболее посещаемых фильмов тех лет не вошли такие замечательные фильмы, как «Баллада о солдате» (Г. Чухрай, 1959), «Сережа» (Г. Аанелия и И. Таланкин, 1960), «Поэма о море» (Ю. Солнцева, 1958) (30, 23 и 10 млн зрителей соответственно) ${ }^{1}$. Таким, образом, развлекательные жанры, по которым так истосковался зритель, вытеснили на задворки серьезные, проблемные картины, ставшие впоследствии классикой советского кинематографа. Надо отметить, что такой выбор сделала в первую очередь молодежь, самая активная зрительская категория. Во время «оттепели» для большинства молодежной киноаудитории (с неполным средним и средним образованием) принципом отбора фильма из репертуара служила мера развлекательности.

Позднее, в 1960-1970-е годы, кинематограф отреагировал на повышенной спрос развлекательности новым жанром, совмещающим в себе опыт цирка, эстрады, оперетты и т. А. «Как и в 1930-е годы, - отмечает искусствовед Н. А. Хренов, - “звездой” экрана становится “звезда" эстрады (В. Кикабидзе, А. Пугачева, С. Ротару, В. Иеонтьев и т. А.). В этом направлении развивается жанр музыкального фильма, или мюзикл. Такой жанр не мог не появиться в кинематографе, поскольку публика немало способ- 
ствовала этому. По сути дела, в те годы развлекательные формы искусства вновь, как это было еще в 20-е годы, начинают переживать настоящий расцвет, отвечая массовым потребностям» (Полюса кинопроцесса ..., 2007: 83-84).

Кинокритика своеобразно отреагировала на успех развлекательного, жанрового кинематографа у широкой зрительской аудитории. В период «оттепели» сформировался особый жанр советской кинокритики - фельетон о коммерческом фильме, преимущественно иностранного производства, но также и собственного. Но, несмотря на все более остро ощутимую конфронтацию между зрителем и критиком, киножурналы, и в первую очередь «Советский экран», продолжали активно читать. И вскоре подобные фельетоны стали вытесняться статьями, в которых учитывалась специфика жанрового кино ${ }^{2}$.

Ориентация на кассу, т. е. на запросы самой широкой аудитории, зачастую приводила к тому, что интересы зрителей, тяготеющих к сложному, интеллектуальному кино, практически не учитывались. «Аифференциация кинотеатров была очень слабой. Только в 60-е годы в Москве, помимо Кинотеатра повторного фильма, рассчитанного на репертуар проката прошлых лет, появился кинотеатр “Иллюзион”, специализировавшийся на отечественной и зарубежной киноклассике. В целом киноклассика, сложные современные фильмы, документальное и научно-популярное кино, мультфильмы плохо доходили до зрителя», - писала М. Р. Зезина (Зезина, 2004: 402).

Социологические исследования тех лет показывают, что независимо от обстоятельств у так называемого трудного фильма в советское время была очень стабильная аудитория. Эта категория зрителей (профессионалы, любители, подготовленная аудитория) была лидером мнения, т. е. непосредственно влияла на общественное признание того или иного авторского фильма (Зезина, 2004; Кино и зритель ... , 1968; Кино и зритель, 1970). В эпоху «оттепели» кинематограф переживал небывалое сближение с этой группой аудитории, чему способствовало появление киноклубов, которые организовывались любителями кино при вузах, НИИ, различных предприятиях. В таких клубах просмотры картин (не только отечественных, но и зарубежных) сопровождались их обсуждением, что значительно повышало коэффициент полезного воздействия кино на зрителя.

«В структуре кинопроката возник новый канал общения с кино, - писал по поводу киноклубов Н. А. Хренов, - пока недостаточно массовый, но в будущем обещающий таковым быть. По сути дела, в те годы в сознании массовой публики удалось оживить сформировавшуюся в первые десятилетия его истории легенду кинематографа. Кстати, способы в формировании ядра массовой публики, связанные с киноклубами, также повторяли некоторые организационное меры 1920-х годов, способствовавшие эстетическому развитию кинопублики. 1920-е годы были связаны с распространением ОАСК - Общества друзей советского кино» (Полюса кинопроцесса ... , 2007: 79-80).

В эпоху «оттепели» даже появились предложения создать аналогичное общество друзей кино, однако они так и не были реализованы ${ }^{3}$. В конце 1950-х годов был разрешен бесплатный показ старых фильмов, которые уже не могли давать кассовых сборов, в учреждениях, школах, институтах. Это замечательное решение сразу показало свой результат. Поскольку телевизоры тогда только входили в быт, для многих, особенно детей и молодежи, эти сеансы были единственной возможностью увидеть замечательные отечественные ленты: «Броненосец “Потемкин” (С. Эйзенштейн, 1925), «Мы из Кронштадта» (Е. Азиган, 1936), «Мать» (В. Пудовкин, 1926), трилогию о Максиме (Г. Козинцев и $\Lambda$. Трауберг: «Юность Максима», 1934; «Возвращение Максима», 
1937, «Выборгская сторона», 1938), «Аепутат Балтики» (А. Зархи и И. Хейфиц, 1936); и др. Список демонстрируемых бесплатно картин постоянно расширялся. Кроме историко-революционных лент в него были включены историко-биографические, экранизации классики, детские.

Как замечает М. Р. Зезина, «возможности посмотреть фильмы вне государственной сети кинопроката существовали, но были весьма ограниченны. В Москве было несколько мест, где такие просмотры проводились для избранной публики - например, в Аоме кино и в некоторых других домах творческой интеллигенции, в цековских и совминовских домах отдыха, в клубах некоторых министерств и ведомств. В учебных целях некоторые современные зарубежные фильмы, не демонстрировавшиеся в прокате, показывали в студенческих аудиториях, во ВГИКе, на факультете журналистики МГУ» (Зезина, 2004: 405).

Надо сказать, что обсуждения просмотренных фильмов, проходящие в рамках киноклубов, в конце 1950 - начале 1960 -х годов еще практически никак не отражались на деятельности кинематографистов.

\section{КИНОСОЦИОАОГИЯ}

В послесталинский период научное изучение зрительской аудитории началось с возрождением конкретно-социологических исследований в 1962 г., когда во ВГИКе был создан факультативный семинар «Кино и зритель». В следующем году возникла лаборатория на общественных началах с таким же названием ${ }^{4}$. Кроме этого, изучением зрительской аудитории занимались журнал «Советский экран» (проводя регулярные анкетирования читателей), социологическая лаборатория Научно-исследовательского кинофотоинститута (НИКФИ), общественный совет при Союзе кинематографистов, созданный в 1957 г., методический комитет при Бюро пропаганды советского киноискусства. Подключились к социологическим исследованиям и кинофикаторы с кинопрокатчиками.

В середине 1960-х годов большое исследование провел коллектив при Уральском филиале АН СССР под руководством $\Lambda$. Н. Когана (Жабский, Тарасов, Фохт-Бабушкин, 2000). 13-16 мая 1968 г. в Москве состоялась расширенная сессия Совета по проблеме «Кино и зритель» Союза кинематографистов СССР. На ней, в частности, выяснилось, что тип «зрителя, ориентированного на развлечения», является «живой непреложной реальностью» (Зоркая, 1981: 120-121), с которой необходимо мириться. Таким образом, развлекательная функция искусства была узаконена в возрождающейся киносоциологии. А вскоре возникли первые попытки общей типологии кинозрителей 5 . Так, согласно одной из них киноаудитория была поделена на два основных типа: активно-деятельное и пассивно-потребительское отношение к искусству. Принципиальное отличие второго типа аудитории от первого заключается в том, что видимое на экране не связано для него с его жизненными позициями, личностно-ролевыми интересами. Наоборот, в кинотеатре он стремится забыть эти роли, отвлечься от них. «Ааже видя в фильме куски реальной жизни, он склонен игнорировать это сходство, - характеризует Н. М. Зоркая, - никакой идентификации зрителя с действующими лицами не происходит. Искусство не воспринимается таким зрителем как система ценностей. Его ожидания и требования к фильму связаны с тем, что происходящее на экране должно смешить или как-то воздействовать на нервы, доставлять ощущения удовольствия, разрядки. Поэтому оно может быть заменено для него другими способами развлечения, проведения досуга, например посещением парка куль- 
туры или футбольного матча» (Зоркая, 1981: 122). Соответственно, первый, активнодеятельный тип аудитории ищет точки соприкосновения между содержанием увиденной картины и собственной жизнью.

Аругое название этих двух категорий: зрители с интровертивным и экстравертивным типами восприятия. Зрители из первой категории во время просмотра пытаются найти необходимые качества, свойства, личностные характеристики героев, которые они могут примерить на себя, как бы приобрести, чтобы стать самим собой. Аля экстравертивного восприятия скорее свойственен процесс примерки, подгонки под образец («а смогу ли я стать таким храбрым, обаятельным, умным, ловким, безжалостным» и т. п.). Аля молодежи более свойственно экстравертивное восприятие.

Социологические исследования «оттепельного» периода опирались, с одной стороны, на уже существующий советский опыт 1920-х годов, а с другой - на опыт работы западных социологов. «В 50-60-е годы, - констатирует М. Р. Зезина, - в зарубежной социологии получили распространение концепции, согласно которым средства массовой коммуникации, в том числе кинематограф, определяют скорее не то, что люди думают, а то, о чем они думают. Исследования, проводимые после просмотра конкретных фильмов, показывали избирательность зрительского восприятия. Зритель пропускал в сознание лишь то, что было заведомо значимо именно для него» (3езина, 2004: 407).

Если соотнести это заявление с приведенной выше классификацией аудитории, то станет ясно, что оно относится к активно-деятельному типу аудитории, ориентированному на сопоставление увиденного в кинозале с личным опытом. Однако это лишь одна из множества граней зрительской аудитории, в то время как советская киносоциология уже в 1960-е годы охватывала ее различные аспекты: мотивы посещения кино, оценки фильмов, состав зрителей и т. А. и т. п.

Активная позиция зрителей по отношению к киноискусству, помимо возникновения киноклубов, проявилась в эпистолярном жанре. Редакции кинематографических журналов и киностудии начали утопать в потоке зрительских писем. Так, на киностудии « $е$ енфильм» их условно делили на четыре группы: «1) письма с требованиями отдать авторов того или иного фильма под суд или привлечь к партийной ответственности, 2) письма-восхищения, 3) письма-возмущения показом на экране обнаженных женщин (максимум, что имелось в виду - чрезмерный вырез платья или нога, открытая выше колена), 4) письма с просьбами помочь сделаться актерами, режиссерами или на худой конец, сценаристами» (Кино и зритель, 1970: 128).

В 1960-х годах согласно социологическим исследованиям зритель предпочитал фильмы, отличающиеся простотой и ясностью кинематографического языка. Среди них особой любовью пользовались комедии, приключенческие фильмы и мелодрамы. Кассовыми чемпионами в это время стали «Бриллиантовая рука» (А. Гайдай, 1968), «Кавказская пленница, или Новые приключения Шурика» (А. Гайдай, 1966), «Свадьба в Малиновке» (А. Тутышкин, 1967), «Операция “Ы” и другие приключения Шурика» $(\Lambda$. Гайдай, 1965$)\left(76,7,76,5,74,6\right.$ и 69,6 млн зрителей соответственно) и др. ${ }^{6}$

Следует отметить, что социологические исследования во все времена, в том числе и в рассматриваемый период, базировались на разных подходах, проводились в разных регионах, в разное время и по различным методикам. Поэтому их результаты часто противоречат друг другу. Так, в приведенном выше списке лидеров советского проката 1960-х годов нет ни одной картины, вошедшей в десятку лучших фильмов 1965 г., названных зрителями Урала (в ходе проведенных там социологических исследований). 
К ним относятся «Председатель» (А. Салтыков, 1964), «Отец солдата» (Р. Чхеидзе, 1964), «Жили-были старик со старухой» (Г. Чухрай, 1964), «Верьте мне, люди» (В. Беренштейн, И. Гурин, А. Ауков, 1964), «Ракеты не должны взлететь» (А. Швачко и А. Тимонишин, 1964), «Государственный преступник» (Н. Розанцев, 1964), «Ганга и Ажамна», (Н. Босе, Индия, 1961), «Как Вас теперь называть?» (В. Чеботарев, 1966), «Свет далекой звезды» (И. Пырьев, 1965), «Гранатовый браслет» (А. Роом, 1964) (Кино и зритель ..., 1968: 170). Общей чертой подавляющего числа приведенных фильмов является то, что в них превалирует не развлекательная, не коммерческая составляющая, а проблемность. Их доминирующим качеством являются не сюжетные коллизии, как в приведенных выше кассовых чемпионах, а характеры, яркие правдивые образы, такие, как, например, Егор Трубников (М. Ульянов) из фильма «Председатель».

Очевидно, коренное различие двух групп фильмов-чемпионов заключается в различии опрашиваемых аудиторий. Основная часть зрителей фильмов-чемпионов типа «Гусарской баллады» (Э. Рязанов, 1962) или «Полосатого рейса» (В. Фетин, 1961) относится к пассивно-потребительскому типу киноаудитории. А зрители, проголосовавшие за такие картины, как «Председатель» или «Жили-были старик со старухой», относятся к активно-деятельному типу. Однако данное деление является условным.

Из зарубежных картин в 1960-х годах в советском прокате лидировали американские и индийские. Из американских лучшую прокатную судьбу имели «Великолепная семерка» (Аж. Стерджес, 1960), «Золото Маккенны» (Аж. Аи Томпсон, 1969) и «Спартак» (С. Кубрик, 1960); из индийских: «Материнская любовь» (А. Сен, 1966), «Аюбовь в Кашмире» (Р. Сагар, 1965) и «Аюбимый раджа» (М. Сегал, 1972)7. Жанровые предпочтения в области зарубежной кинопродукции были аналогичны предпочтениям советских фильмов. В почете были приключения и мелодрама. И, что особенно важно, в зарубежных фильмах наши зрители искали и ценили зрелищность.

Кроме этого, большим успехом у зрителей в годы «оттепели» пользовалось европейское кино - фильмы итальянского неореализма (особенно полюбились советской

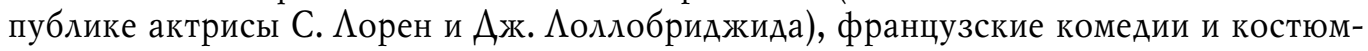
ные драмы (например, фильм Б. Бордери «Три мушкетера», 1961), венгерские, польские фильмы, особенно на военную тематику.

\section{ЗАКАЮЧЕНИЕ}

Кинорепертуар «оттепельного» периода был очень разнообразным, что не могло не сказаться на кинопосещаемости. Как мы сказали, в это время у нас была самая высокая посещаемость за всю историю страны. Репертуарная политика «оттепельного » кино была ориентирована на зрителя. Большое внимание уделялось развлекательной составляющей. Но это делалось (за редким исключением) не в угоду общему качеству картины. Если проводить параллели с настоящим временем, то нетрудно заметить, что сегодня развлекательная функция кино превалирует, а все остальные (воспитательная, просветительская и пр.) остаются далеко позади или чаще вообще игнорируются создателями фильмов (как российских, так и зарубежных).

Особое внимание в годы «оттепели» уделялось киносоциологии. Изучением зрительской аудитории, ее предпочтений и восприятия того или иного фильма занималась масса различных организаций. Сегодня же этими исследованиями занимаются лишь некоторые энтузиасты, системного мониторинга и анализа киноаудитории не проводится. Во многом по этой причине существующий кинорепертуар не удовлетворяет зрительские потребности. 
Таким образом, для решения существующих сегодня проблем, связанных с диссоциацией отечественного кинематографа и зрителя, необходимо обратиться к истории. А точнее - к наиболее успешным и потому привлекательным для исследователей периодам, одним из которых является эпоха «оттепели», когда у нас была самая высокая кинопосещаемость.

\section{ПРИМЕЧАНИЯ}

${ }^{1} \mathrm{~B}$ то же время согласно результатам анкетирования читателей «Советского экрана» «Сережа» был назван лучшим советским фильмом 1960 г. Среди других картин зрители особо отметили следующие фильмы: «Живые герои» (Б. Браткаускас, М. Гедрис, 1959), «Колыбельная» (М. Калик, 1959), «Неотправленное письмо» (М. Калатозов, 1959).

2 Е. Карцева, В. Славкин, М. Блейман и др.

3 Такое «Общество друзей кино» появилось уже после перестройки в 1989 г.

${ }^{4}$ В 1967 г. она получила штатное расписание и экспериментальную базу - московский кинотеатр «Уран».

5 В материалах конкретно-социологического исследования «Киноискусство и массовая аудитория», проведенного в Эстонской Советской Социалистической Республике в 1971 г. Институтом конкретных социальных исследований АН СССР, характерными признаками «зрелищно-развлекательной» культуры названы: распространение по каналам массовой коммуникации; способность служить предметом потребления у самых многочисленных и разнородных (по географическим и социально-культурным координатам) групп населения; стандартность и стереотипность произведений, однородность содержания (гомогенизация) и стереотипность приемов, связанная с задачей удовлетворить требования разнородной публики; невключенность в систему эстетического просвещения и воспитания (цит. по: Зоркая, 1981: $121-122)$.

6 «Щит и меч» (1-я серия - 68,3 млн, 2-я серия - 66,3 млн зрителей), «Новые приключения неуловимых» (66,2 млн), "А зори здесь тихие...» (по 66 млн на серию), «Человек-амфибия» $(65,4$ млн), «Война и мир» (1-я часть - 58,3 млн, 2-я часть - 58,0 млн), «Сильные духом» (1-я серия - 55,2 млн, 2-я серия - 54,6 млн), «Неуловимые мстители» (54,5 млн), «Трембита» (51,2 млн), «Бабье царство» (49,6 млн), «Гусарская баллада» $(48,6$ млн), «Путь в Сатурн» (48,2 млн), «ЧП - Чрезвычайное происшествие» (по 47,4 млн на серию), «Щит и меч» (3-я серия - 46,9 млн, 4-я серия - 46,9 млн), «Простая история» (46,8 млн), «Оптимистическая трагедия» (46,0 млн), «Полосатый рейс» $(45,8$ млн).

7 Среди зарубежных картин лидерами советского проката в 1960-х годах были следующие: «Великолепная семерка», США (67 млн зрителей на серию); «Золото Маккенны», США (63 млн на серию); «Спартак», США (1-я серия - 63 млн, 2-я серия - 59 млн); «Материнская любовь», Индия (1-я серия - 52,1 млн, 2-я серия - 51,8 млн); «Верная Рука - друг индейцев», ФРГ СФРЮ (46,5 млн); «Фантомас», Франция - Италия (45,5 млн); «Фантомас разбушевался» (44,7 млн); «Анжелика - маркиза ангелов», Франция - Италия - ФРГ (44,1 млн); «В джазе только девушки» / «Некоторым нравится погорячее», США (43,9 млн); «Анжелика и король» (43,3 млн); «Июбовь в Кашмире», Индия, 1965 (40,6 млн); «Июбимый раджа», Индия (40,1 млн на серию); «Четыре дороги»/ «Четыре сердца, четыре дороги», Индия (39,8 млн на серию); «Сокровище Серебряного озера», ФРГ - СФРЮ - Франция (39,8 млн); «Королева Шантеклера», Испания (39,7 млн).

\section{СПИСОК АИТЕРАТУРЫ}

Жабский, М. И. (2009) Социокультурная драма кинематографа. Аналитическая летопись (1969-2005 гг.). М. : «Канон+» РООИ «Реабилитация». 775 с.

Жабский, М. И., Тарасов, К. А., Фохт-Бабушкин, Ю. У. (2000) Кино в современном обществе : Функции - воздействие - востребованность / М-во культуры Рос. Федерации. Науч.исслед. ин-т киноискусства. М. : Белый берег. 375 с. 
Зезина, М. Р. (2004) Кинопрокат и массовый зритель в годы «оттепели» // История страны. История кино/ ред. С. С. Секиринский. М. : Знак. 496 с. С. 389-412.

Зоркая, Н. М. (1981) Уникальное и тиражированное: средства массовой информации и репродуцированное искусство. М. : Искусство. 167 с.

Зоркая, Н. М. (1994) Фольклор. Иубок. Экран. М. : Искусство. 238 с.

Зоркая, Н. М. (1998) Крутится, вертится шар голубой: Аесять шедевров советского кино. М. : Знание. 192 с.

История киноотрасли в России: управление, кинопроизводство, прокат (2012) / ред. В. И. Фомин. М. : Минкульт РФ ; ВГИК. 2759 с.

Кинематограф оттепели. Аокументы и свидетельства (1998) / сост. В. И. Фомин. М. : Материк. 458 с.

Кино и зритель (1970) : Материалы расширенной сессии Совета по проблеме «Кино и зритель», состоявшейся 13-16 мая 1968 г. М. : Искусство. 157 с.

Кино и зритель : Опыт социологического исследования (1968) / $\Lambda$. Н. Коган, Г. А. Томилов, В. С. Цукерман, В. И. Волков. М. : Искусство. 327 с.

Иетопись российского кино, 1946-1965 (2010) / рук. проекта В. И. Фомин ; отв. ред. А. С. Аерябин ; сост.: П. В. Фионов, А. С. Аерябин, В. И. Фомин и др. М. : «Канон+» РООИ «Реабилитация». $694 \mathrm{c.}$

Полюса кинопроцесса: притяжение и отталкивание (2007) / под общ. ред. М. И. Жабского ; Федеральное агентство по культуре и кинематографии, Науч.-исслед. ин-т киноискусства. М. : Науч.-исслед. ин-т киноискусства. 438 с.

Рондели, $\Lambda$. А. (2013) Кино и его аудитория : аналитическая летопись взаимоотношений 1969-2010 гг. М. : Науч.-исслед. ин-т киноискусства ; ВГИК. 441 с.

Феномен массовости кино (2004) / под ред. М. И. Жабского. М. : Мин-во культуры ; Науч.исслед. ин-т киноискусства. 367 с.

Фомин, В. И. (1996) Кино и власть. Советское кино, 1965-1985 гг. : Аокументы, свидетельства, размышления. М. : Материк. 371 с.

Фомин, В. И. (2012) Правда сказки. Кино и традиции фольклора. М. : «Канон+» РООИ «Реабилитация». $456 \mathrm{c.}$

Фохт-Бабушкин, Ю. У. (2001) Искусство в жизни людей: конкретно-социологические исследования общества в России второй половины XX века. История и методология. СПб. : Алетейя. $556 \mathrm{c.}$

Хренов, Н. А. (2002) Публика в истории культуры. М. : Гос. ин-т искусствознания. 496 с.

Аата поступления: 2.07.2015 г.

\section{CINEMA REPERTOIRE AND AUDIENCE PREFERENCES DURING THE THAW IN RUSSIA \\ M. I. KOSINOVA \\ (STATE UNIVERSITY OF MANAGEMENT;}

\section{S. A. Gerasimov All-Russian State Institute of Cinematography, Moscow)}

In this article, we focus on the period of the Thaw, which is considered the golden age of Soviet cinema, when it attracted the eye of both domestic and global audiences. During this period, Russia witnessed the highest cinema attendance throughout the whole history of the Soviet cinema (about 4 billion visits per year). Given the current deplorable state of the national cinematography, its unpopularity among the audience, the experience of this peak time in the history of Russian cinema may prove most useful, instructive and relevant.

The aim of this article is to identify the reasons for the success of the cinema among its audience during the years of the Thaw. This will help us assess the course of the modern repertoire policy of the Russian cinema, and give recommendations on how to better direct it to its audience and close the gap between the national cinema and its viewers. In order to make it possible, we have to study the reper- 
toire policy of the cinema of the Thaw, and also take a deeper look at sociological studies of movie audience and at the critical thought of the period.

The repertory policy of the cinema during the given period was viewer-oriented. Special attention was paid to entertainment as a constituent part of the art of the cinema. But this was almost never at the expense of the overall quality of the movie. A comparison with the present time will easily show that in today's movies, entertainment function prevails, and those of education or personality development lag far behind or, more frequently, are completely ignored by the filmmakers (both Russian and foreign).

The wide success of entertainment and genre cinema contributed to the rise of a special genre of Soviet film criticism - a review of a commercial movie, mostly foreign-made, but also domestic, followed by articles which dealt with the specifics of the genre movie. Sociological studies conducted during the Thaw show that, regardless of the circumstances, the so-called "difficult film" had a very stable audience. These viewers (professionals, amateurs, prepared audience) acted as opinion leaders, directly influencing the public recognition of movies. This contributed to the emergence of film societies, organized by movie fans in universities, research institutes and various enterprises. Film screenings there were accompanied by discussions, which greatly increased the impact of the movie on its audience.

Keywords: history of cinema; Russian cinema; Thaw; repertoire policy; film viewer; cinema audience; cinema attendance; film distribution

\section{REFERENCES}

Zhabskii, M. I. (2009) Sotsiokul'turnaia drama kinematografa. Analiticheskaia letopis' (1969-2005 gg.) [Sociocultural drama of cinematography. An analytical chronicle (1969-2005)]. Moscow, "Kanon+" Publ., RPOD "Reabilitatsiia". 775 p. (In Russ.).

Zhabskii, M. I., Tarasov, K. A. and Fokht-Babushkin, Yu. U. (2000) Kino v sovremennom obshchestve: Funktsii - vozdeistvie - vostrebovannost' [Cinema in the modern society: Functions - impact relevance]/ Ministry of Culture of the Russian Federation, Research Institute of Cinema Art. Moscow, Belyi bereg Publ. 375 p. (In Russ.).

Zezina, M. R. (2004) Kinoprokat i massovyi zritel' v gody «ottepeli» [Film distribution and the mass audience during the "Thaw"]. In: Istoriia strany. Istoriia kino [The history of the country. The history of filmmaking] / ed. by S. S. Sekirinskii. Moscow, Znak Publ. 496 p. Pp. 389-412. (In Russ.).

Zorkaia, N. M. (1981) Unikal' noe i tirazhirovannoe: sredstva massovoi informatsii i reprodutsirovannoe iskusstvo [The unique and the replicated: Mass media and reproduced art]. Moscow, Iskusstvo Publ. 167 p. (In Russ.).

Zorkaia, N. M. (1994) Fol'klor. Lubok. Ekran [Folklore. Cheap print. Screen]. Moscow, Iskusstvo Publ. 238 p. (In Russ.).

Zorkaia, N. M. (1998) Krutitsia, vertitsia shar goluboi : Desiat' shedevrov sovetskogo kino [The blue ball is spinning, turning: Ten masterpieces of the Soviet cinema]. Moscow, Znanie Publ. 192 p. (In Russ.).

Istoriia kinootrasli $v$ Rossii: upravlenie, kinoproizvodstvo, prokat [The history of the film industry in Russia: Management, production, distribution] (2012) / ed. by V. I. Fomin. Moscow, Ministry of Culture of the RF ; All-Russian State Institute of Cinematography Publ. 2759 p. (In Russ.).

Kinematograf ottepeli. Dokumenty $i$ svidetel'stva (1998) [Cinema in the Thaw. Documents and evidence]/ ed. by V. I. Fomin. Moscow, Materik Publ. 458 p. (In Russ.).

Kino i zritel' : Opyt sotsiologicheskogo issledovaniia [Cinema and its audience : A sociological study] (1968) / L. N. Kogan, G. A. Tomilov, V. S. Tsukerman and V. I. Volkov. Moscow, Iskusstvo Publ. 327 p. (In Russ.).

Kino $i$ zritel' [Cinema and its audience] (1970) : Proceedings of the extended session of the Council on the issue "Cinema and Its Audience", May 13-16, 1968]. Moscow, Iskusstvo Publ. 157 p. (In Russ.). 
Letopis' rossiiskogo kino, 1946-1965 [A chronicle of the Russian cinema, 1946-1965] (2010) / project manager V. I. Fomin ; ed. by A. S. Deriabin ; comp.: P. V. Fionov, A. S. Deriabin, V. I. Fomin et al. Moscow, "Kanon+" Publ., RPOD "Reabilitatsiia". 694 p. (In Russ.).

Poliusa kinoprotsessa: pritiazhenie $i$ ottalkivanie [Poles of cinematography: Attraction and repulsion] (2007) / ed. by M. I. Zhabskii ; Federal Culture and Cinematography Agency, Research Institute of Cinema Art. Moscow, Research Institute of Cinema Art Publ. 438 p. (In Russ.).

Rondeli, L. D. (2013) Kino $i$ ego auditoria : analiticheskaia letopis' vzaimootnoshenii 1969-2010 gg. [Cinema and its audience: An analytical chronicle of interactions, 1969-2010]. Moscow, Research Institute of Cinema Art Publ. ; All-Russian State Institute of Cinematography Publ. 441 p. (In Russ.).

Fenomen massovosti kino [The phenomenon of mass cinema] (2004) / ed. by M. I. Zhabskii. Moscow, Ministry of Culture of the RF ; Research Institute of Cinema Art Publ. 367 p. (In Russ.).

Fomin, V. I. (1996) Kino i vlast'. Sovetskoe kino, 1965-1985 gg. : Dokumenty, svidetel'stva, razmyshleniia [Cinema and power. The Soviet cinema, 1965-1985 : Documents, records, reflections]. Moscow, Materik Publ. 371 p. (In Russ.).

Fomin, V. I. (2012) Pravda skazki. Kino i traditsii fol'klora [The truth of the fairy tale. Cinema and the traditions of folklore]. Moscow, "Kanon+" Publ., RPOD "Reabilitatsiia". 456 p. (In Russ.).

Fokht-Babushkin, Yu. U. (2001) Iskusstvo $v$ zbizni liudei: konkretno-sotsiologicheskie issledovaniia obshchestva $v$ Rossii vtoroi poloviny XX veka. Istoriia i metodologiia [Art in people's lives: Specific sociological studies of the Russian society in the second half of the 20th century. History and methodology]. St. Petersburg, Aleteiia Publ. 556 p. (In Russ.).

Khrenov, N. A. (2002) Publika v istorii kul' tury [The audience in the history of culture]. Moscow, State Institute of Art Studies Publ. 496 p. (In Russ.).

Submission date: 2.07 .2015$.

Косинова Марина Ивановна - кандидат философских наук, доцент кафедры управления в сфере культуры, кино, телевидения и индустрии развлечений Государственного университета управления; доцент кафедры продюсерского мастерства и менеджмента Всероссийского государственного института кинематографии им. С. А. Герасимова; член Союза кинематографистов РФ. Адрес: 109542, Россия, г. Москва, Рязанский проспект, А. 99. Тел.: +7 (495) 371-23-88. Эл. адpec: kosimarina@yandex.ru

Kosinova Marina Ivanovna, Candidate of Philosophy, Associate Professor, Department of Management in Culture, Film, Television and Entertainment Industry, State University of Management; Associate Professor, Department of Production Art and Management, S. A. Gerasimov All-Russian State Institute of Cinematography; Member, Union of Cinematographers of the Russian Federation. Postal address: 99 Ryazansky Prospekt, 109542 Moscow, Russian Federation. Tel.: +7 (495) 371-23-88. E-mail: kosimarina@yandex.ru 